\title{
ESTILOS
}

DOI: https://doi.org/10.11606/issn.1981-1624.v26i3 p616-631.

\section{Experiência institucional}

\section{Pontes na assistência social: a criação de um dispositivo de cuidado entre juventudes}

\author{
Danielle Kepe de Souza Pinto; Jaquelina Maria Imbrizi
}

Resumo. A preceptoria de estagiários do curso de psicologia no Sistema Único de Assistência Social é um desafio profissional, especialmente quando os estudantes são jovens universitários exercitando práticas de cuidado com crianças e adolescentes cujas famílias são usuárias do Centro de Referência de Assistência Social. O objetivo deste artigo é relatar, da perspectiva da preceptora, a experiência de estágio curricular pautada na escuta territorial da dimensão sociopolítica do sofrimento. A partir do convite aos participantes realizaram-se caminhadas pela cidade seguidas de discussões em grupo das quais emergiram questões sobre violência cotidiana, violações de direito e o desamparo discursivo dos sujeitos em situações sociais críticas. Nessas atividades foi possível criar um dispositivo de (auto)cuidado e provocar marcas na formação profissional com vistas à transformação social.

Palavras-chave: assistência social; juventude; estágio curricular; escuta territorial; sofrimento sociopolítico.

\section{Puentes en la asistencia social: la creación de un dispositivo de atención entre jóvenes}

Resumen. Preceptuar pasantes del curso de psicología en el Sistema Único de Asistencia Social es un desafío profesional, especialmente cuando los estudiantes son jóvenes universitarios que ejercen prácticas de cuidado con niños y adolescentes cuyas familias utilizan el Centro de Referencia Asistencial. El objetivo de este artículo es comunicar, de la perspectiva de la preceptora, la experiencia de una pasantía curricular basada en la escucha territorial de la dimensión sociopolítica del sufrimiento. A partir de la invitación a los participantes, se realizaron caminatas por la ciudad seguidas de discusiones grupales de las cuales surgieron cuestiones sobre la violencia cotidiana, las violaciones de derechos y el desamparo discursivo de los sujetos en situaciones sociales críticas. En esas actividades se logró crear un dispositivo de (auto)cuidado y marcar la formación profesional con miras a la transformación social.

Descriptores: asistencia social; juventud; pasantía curricular; escucha territorial; sufrimiento sociopolítico.

\footnotetext{
* Psicóloga, trabalhadora do Sistema Único de Assistência Social em um Centro de Referência de Assistência Social, São Vicente, SP, Brasil. E-mail: danny_kepe@hotmail.com

** Professora associada da Universidade Federal de São Paulo (UNIFESP), Campus Baixada Santista, Santos, SP, Brasil. E-mail: jaquelina.imbrizi@unifesp.br
} 


\title{
Bridges in social assistance: the creation of a care device between different youth groups
}

\begin{abstract}
The tutoring of interns from the psychology course in the National Social Assistance System is a professional challenge, especially when those interns are young university students exercising care practices with children and adolescents whose families are users of the Social Assistance Reference Center. The purpose of this article is to report, from the tutor's perspective, the experience of a curricular internship based on territorial listening to the sociopolitical dimension of suffering. Incited by an invitation, the participants took walks around the city followed by group discussions from which issues emerged about daily violence, violations of rights and the discursive helplessness of the subjects in critical social situations. In these activities, it was possible to create a (self)care device and to cause marks in the professional training that contemplate social transformation.
\end{abstract}

Key words: social assistance; youth; curricular internship; territorial listening; sociopolitical suffering.

\section{Des ponts dans l'aide sociale: la création d'un dispositif de soin entre jeunesses}

Résumé. Le préceptorat de stagiaires du cours de psychologie dans le Système Unifié d'Assistance Sociale est un défi professionnel, en particulier pour des étudiants universitaires prenant en charge des enfants et adolescents. L'objectif de cet article est de rapporter, du point de vue du précepteur, l'expérience d'un stage curriculaire basé sur l'écoute territoriale de la dimension socio-politique de la souffrance. Des promenades dans la ville ont été réalisées, suivies de discussions en groupe avec les participants invités. Les questions qui en sont ressorties sont: la violence quotidienne, les violations de droits et la détresse discursive des sujets en situation sociale critique. Lors de ces activités, il a été possible de créer un dispositif de (auto) soins et de créer des marques dans la formation professionnelle en vue de la transformation sociale.

Mots-clés: assistance sociale; jeunesse; stage curriculaire; écoute territoriale; souffrance sociopolitique.

C omo um percurso construído por partidas, rotas e chegadas, este relato de experiência sobre a preceptoria de estudantes do curso de psicologia tem sua origem em vivências anteriores, em que o fio condutor foi um mestrado profissional, realizado entre 2015 e 2017 (Pinto, 2017). A pesquisa se sustentou na experimentação de uma das autoras, psicóloga e trabalhadora do Sistema Único de Assistência Social (SUAS) de São Vicente/SP, e na hipótese inicial de um estranhamento dos profissionais de Psicologia no que se refere ao seu papel nos serviços socioassistenciais, que se assemelhava à metamorfose vivida por um dos principais protagonistas do escritor austro-húngaro Frank Kafka (1883-1924). Na obra kafkiana $A$ metamorfose, Gregor Samsa é transmutado repentinamente em um inseto monstruoso e tem que lidar com os reflexos dessa mudança inesperada em seus movimentos, pensamentos e relações. Em uma ficção de enredo inverossímil, irreversível e não linear, o autor lança seu leitor no desabrigo de um contexto totalmente estranho (Kafka, 1997).

O mestrado apontou, na ocasião, que os psicólogos se reconheciam no personagem-inseto pela percepção da mudança abrupta de um "corpo" profissional na assistência social, seja por ser uma área relativamente recente não contemplada na formação, de impedimento de uma clínica padrão do consultório particular, mas, principalmente, por ser um campo marcado por práticas burocráticas extenuantes que tendem a coisificar as relações estabelecidas, tornando os contatos pessoais inumanos, logo propulsores de um intenso mal-estar para os psicólogos. Ficou expressa a necessidade de criação de novos fazeres pelos psicólogos nos serviços da assistência social que o tirassem desse lugar desumanizado e desumanizante.

Essa problematização da atuação do psicólogo no SUAS não é incomum, sendo inclusive pauta de discussão contínua do conselho de classe (Conselho Federal de Psicologia, 2007; 2011; 
2013), considerando sua crescente incorporação profissional nas equipes socioassistenciais nesses 15 anos de existência. Essas discussões, por vezes, são marcadas por questões muito objetivas do trabalho, da aplicação das normativas específicas do universo socioassistencial. A obra kafkiana foi um ponto de partida para refletir sobre as nuances desse possível esmaecimento identitário no contexto socioassistencial, trazendo para as reflexões elementos literários em consonância com um cotidiano pesado, inacabado, estrangeiro, de um conforto no desconfortável (Adorno, 1998; Benjamin, 1985), que travam diálogos possíveis com a consolidação movediça do SUAS.

A pesquisa de mestrado indicou a necessidade de rever a prática profissional na assistência social da cidade, assim como a formação em Psicologia para atuação em políticas públicas direcionadas às transformações sociais na região. $\mathrm{O}$ estudo previu, como um dos produtos, contribuir com os subsídios teóricos e práticos para a formação continuada de psicólogas(os) e futuras(os) psicólogas(os), inspirando, em 2018, um projeto piloto de estágio que articulava a universidade com um dos Centro de Referência de Assistência Social (CRAS) do município, então serviço de atuação da pesquisadora, pretendendo relacionar ensino, estágio e pesquisa na região, mas sem perder de vista as indispensáveis reverberações da proposta no campo de atuação, logo na formação continuada no SUAS.

O estágio foi realizado no decorrer daquele mesmo ano e contou com o exercício de três estagiários do $4^{\mathrm{o}}$ ano de Psicologia, a supervisora/professora, o psicólogo da universidade e a preceptora. Experimentamos a construção de um dispositivo de escuta em formato de rodas de conversa, com intervenções com crianças e adolescentes de famílias usuárias do CRAS, em um processo vivo, dinâmico e de constante reconstrução. O artigo tem o objetivo de apresentar o relato de experiência desse estágio, sob a perspectiva da preceptora, com as reflexões que emergiram do processo, pelas apreensões do campo e do espaço de supervisão e pelas inquestionáveis marcas deixadas na equipe, nos estagiários, nos jovens e na própria preceptora.

Articulado com outros projetos em comum desenvolvidos na Universidade, sustentado em uma ética da psicanálise transposta para o campo social, o estágio pretendeu oferecer a escuta territorial (Broide \& Broide, 2015) a sujeitos em situações sociais críticas, submetidos à violação de seus direitos por parte do Estado. Foi criado um dispositivo grupal que interveio nas dimensões sociais, institucionais e subjetivas, atuando norteado pelos conceitos fundamentais das intervenções psicanalíticas clínico-políticas (Rosa, 2016).

Assim como na pesquisa de mestrado, por entender sua potência, tomamos novamente emprestadas contribuições da obra de Kafka para olhar as práticas da assistência social, mas desta vez como recurso para discutir questões do estágio e por meio do breve conto "A ponte" (Kafka, 1985), de narrativa marcada por percursos duros, intensos e, muitas vezes, incomunicáveis. Tal qual no conto, dividiremos nossa trajetória (como a do protagonista da narrativa) em três momentos ápices que serão nossos tópicos seguintes, nos quais traremos, além dos elementos literários e rastros da experiência, o embasamento teórico e as escolhas metodológicas, que trazem sentido ao relato.

\section{Ponto inicial ou uma ponte estendida}

Rígido e frio, eu era uma ponte, uma ponte estendida sobre o abismo. Deste lado estavam as pontas dos pés, do outro as mãos, que eu metera pelo barro adentro a fim de segurar-me. As abas de minha casaca tremulavam-me nos flancos. Lá no fundo corria, ruidoso, o gélido 
riacho de trutas. Turista algum errava por aquelas alturas intransitáveis; a ponte ainda não figurava nos mapas. - Assim, ali estava eu à espera; cumpria-me esperar. Sem desabar, ponte nenhuma pode, uma vez erigida, deixar de ser ponte. (Kafka, 1985, p. 156)

Partindo de uma metáfora absoluta, deparamos com a figura ambígua desta outra personagem kafkiana: uma ponte, que marca a tensão de sua condição ambivalente, humana (estendida com mãos, pés e vestimentas) e não humana (sobre um abismo rochoso); uma ponte que traz características de sua materialidade (estendida e rígida) e, possivelmente, de seu caráter sentimental (firme e frio), e carrega a circunstância de um percurso solitário, de espera, não territorializado (não figura nos mapas e ninguém se aventura em seu trajeto) e imodificável (ponte nenhuma pode deixar de ser ponte). Utilizamo-nos desse ponto inicial, de uma ponte que se estende em condições tão peculiares, para apresentar as características do campo, de nosso público-alvo e da entrada dos estagiários nesse contexto que possui tantas marcas.

O CRAS, em linhas gerais, é uma unidade estatal da proteção social básica do SUAS, que tem por objetivo primordial a prevenção de situações de risco por meio do desenvolvimento de potencialidades, habilidades e competências, e o fortalecimento dos vínculos familiares e comunitários. Ele se coloca como o primeiro acesso de famílias e indivíduos aos direitos socioassistenciais e como responsável pela organização local dos serviços socioassistenciais; apresenta como condição essencial e indispensável o funcionamento do serviço de Proteção e Atenção Integral à Família (PAIF); é de lógica territorial e busca a redução das desigualdades apoiada na mitigação de situações de vulnerabilidade (Conselho Nacional de Assistência Social, 2005). Nesse sentido, o CRAS significaria a presença do Estado nos territórios de maior vulnerabilidade, com caráter universal pela abrangência, mas particular por considerar as especificidades, as diferentes realidades sociais, econômicas, culturais e étnicas, indo muito além de uma ideia de presença, mas como espaço concreto para (re)fazer histórias de vida.

O CRAS sobre o qual nos debruçamos neste relato é um equipamento relativamente recente, inaugurado após muita pressão popular ao final de 2013, em conferências municipais da assistência social. Antes de sua implantação já existiam serviços de proteção básica no município, e as famílias do território eram atendidas no centro da cidade, a uma distância muito maior do que as possibilidades de um deslocamento sem veículos, portanto muito fora de seu território. $\mathrm{O}$ equipamento foi inaugurado abaixo do mínimo de exigências, com apenas uma assistente social e uma auxiliar administrativa, recebendo mais pessoas bem depois, mas sempre em uma equipe reduzida. As equipes nunca foram duradouras, sempre havendo transferências por decisão da gestão ou mesmo pela recusa de trabalho no território, tido como "difícil". Alguns poucos estagiários passaram pelo serviço, sendo a questão do estágio comumente vista como um trabalho adicional ao profissional.

O espaço físico institucional sempre sofreu percalços: a primeira sede tinha problemas sanitários, como infestação de bichos e precisou ser substituída rapidamente; o segundo local ficava distante das famílias mais vulneráveis e padecia de problemas de umidade e vazamentos de água; o terceiro local, ativo no momento do estágio, era bem situado, porém a estrutura não atendia a questões de sigilo para escutas particularizadas, em moldes improvisados.

O bairro principal do território é um dos mais antigos e populosos da cidade. É um espaço que passou por diversas transformações e impactos, com diques criados para retificar seus cursos d'água e a instalação de um depósito de lixo, comumente chamado "lixão", que por muitos anos sacrificou a população e os ecossistemas local e regional. Com ampla área de favelas, com assentamentos precários, que reúnem uma das piores condições de habitabilidade 
e salubridade da cidade, o território tem como características famílias numerosas, com muitas crianças e jovens, chefiadas por mulheres, com trabalhos informais (algumas com histórico familiar no trabalho no "lixão" ou na reciclagem) e baixa renda. Há desemprego, trabalho infantil, tráfico de drogas e diversas formas de violência. Mesmo nesse cenário, sua população nunca foi considerada apática ou não participativa: ao contrário, reconhece-se um caráter reivindicatório e potente, com a presença de lideranças comunitárias que não passam despercebidas à atenção de aspirantes e representantes políticos e que garantiram, inclusive, a implantação do serviço no território.

O CRAS, previsto para atender até 5.000 famílias em sua abrangência (Ministério do Desenvolvimento Social e Combate à Fome, MDS, 2006), rapidamente superou esse número, cobrindo doze bairros e, em 2018, chegando à marca de 10.000 famílias referenciadas, tendo o território o acréscimo de conjuntos habitacionais e a vinda de famílias de outras cidades para sua composição. Assim, mesmo tendo como norte o serviço PAIF, sua execução era impossibilitada pelo número de famílias com necessidade de acesso, além da administração direta dos programas de transferência de renda. O principal programa, ainda em execução no país, trata-se do Bolsa Família, que visa um complemento de renda conforme a configuração da família, articulado com o acesso a direitos e outras ações que estimulam seu desenvolvimento. O programa prevê compromissos com a assistência social, saúde e educação (MDS, 2012).

Assim, o CRAS se tornou um balcão burocrático em que as responsáveis pelo benefício, geralmente as mulheres, buscavam acesso ou questionavam os motivos de bloqueio ou suspensão do complemento de suas rendas - um espaço com atmosfera queixosa semelhante à de grandes repartições públicas, em que a frustração e o distanciamento sempre pareceram prevalecer entre usuários e trabalhadores.

Uma das maneiras complementares de aproximação do PAIF é o Serviço de Convivência e Fortalecimento de Vínculos (SCFV), baseado na divisão dos usuários em grupos pela faixa etária e especificidades dos ciclos de vida, que participam de encontros planejados coletivamente como forma de incentivo de socialização e convivência familiar e comunitária (MDS, 2013). Na cidade, sempre foi comum a realização dos grupos de SCFV ou atividades similares por organizações não governamentais (ONGs), que com o advento do SUAS estreitaram seus laços com os CRAS, mesmo que com reservas. A execução direta do serviço sempre foi vista como um impedimento, haja vista os poucos trabalhadores do serviço e a alta demanda, especialmente por benefícios.

Em 2016, foi realizada a primeira tentativa de oferta direta de um SCFV pelos CRAS do município. Na circunstância, optou-se pelas atividades dentro do equipamento, mas com acompanhamento direto de um profissional contratado como educador social, e não os técnicos do serviço. Ao CRAS cabia apenas oferecer uma responsável para facilitação e mediação das propostas, e nesse ponto do percurso, a história profissional da preceptora dialogava com a do serviço por ter assumido esse papel de técnica do SCFV no CRAS em questão.

$\mathrm{Na}$ oportunidade, o grupo foi montado para adolescentes de 12 a 18 anos incompletos de famílias acompanhadas pelo CRAS, especialmente aquelas com vivência de episódios de violência, trabalho infantil, experiência de acolhimento institucional e/ou outras formas de violação de direitos. Com possibilidade de até sessenta jovens, trinta para o período da manhã e trinta para o período da tarde, duas vezes por semana, o grupo foi de fato composto por 12 a 15 adolescentes, meninos e meninas, com idades de 12 a 15 anos. A montagem do grupo teve 
como dificultador o desconhecimento da importância do SCFV pelas famílias e pela equipe, em um pensamento compartilhado de que seria mais importante uma atividade com caráter produtivo, como um curso profissionalizante, do que um "simples" encontro para convivência entre juventudes.

Além dessa conjuntura, foram vivenciadas dificuldades de acesso dos adolescentes aos encontros, tanto porque foi o momento em que o CRAS ficou distante dos bairros mais vulneráveis, quanto por conta de enchentes que impediam o acesso dos jovens $\mathrm{e}$ impossibilitavam o funcionamento adequado da própria unidade, além dos problemas estruturais do equipamento, como falta da sala coletiva em todas as datas previstas. Apesar disso, observamos a participação ativa dos jovens na rotina do CRAS, nos eventos e passeios propostos, um aumento de vínculo entre eles e a equipe, de modo que o grupo resistiu até o final daquele ano, quando a gestão, alterada após eleições, decidiu descontinuá-lo, alegando novamente excessiva demanda de serviço.

Mas o SCFV ficou na memória afetiva daqueles jovens e futura preceptora, sendo constantemente rememorado pela potência e afeto experimentados naquele ano, assim como o desfecho de contornos inacabados. Com a proposta de estágio suscitada após a finalização do mestrado, em 2018, e a chegada dos estagiários ao campo, essa foi uma das possibilidades abertas, embora não decidida de imediato, pois o campo padecia de diversos enrijecimentos.

Os estagiários precisaram conhecer o campo, a equipe, a rede assistencial e as contrariedades inerentes à prática. Para isso acompanharam a recepção, as reuniões, a espera e o atendimento dos usuários realizados tanto pela preceptora quanto pelos outros profissionais. Em todos os cenários houve a menção do caráter burocrático, sôfrego e a necessidade de criar um novo campo de ação no serviço. Assim, recuperou-se o contato com duas das jovens que tinham participado do SCFV, em 2016, de 16 e 18 anos, com o objetivo de que elas conhecessem os jovens estagiários e lhes apresentassem o território, físico e simbólico.

O caminhar pelas ruas do entorno do CRAS permitiu a convivência entre juventudes em posições diferentes, os que as desconheciam (estagiários) passando a conhecê-las por meio de quem as apresentava (juventude periférica), possivelmente pela primeira vez, referências e trajetórias enlaçadas por narrativas de vida. "Rua é tal como um sonho, nela está expressa toda dramática do desejo e da vida, por meio da figuração, da mudança de uma imagem em outra, do deslocamento e das condensações em cujos fatos, atitudes, gestos, olhares, vida e morte se dão" (Broide \& Broide, 2010, p.13). De um lado, os estagiários traziam relatos das tramas contadas, de conflitos e cenas de violência, questões de gênero e atravessamentos das instituições; de outro, as adolescentes apenas se orgulhavam de (re)conhecer tão bem aquele espaço, de contar sobre o seu dia a dia de tantas nuances, do que viam, ouviam e viviam, expressões recorrentes de vida e morte - e como um fio que ligava ambas as falas, estava o desejo comum de criar outro espaço de expressão para juventudes que tivesse o CRAS como uma das possibilidades.

E talvez estivesse ali estendida a ponte para a juventude em situação de vulnerabilidade, que colocava seu corpo à mostra e se permitia percorrer como um espaço ainda não mapeado, não notado para compor os desenhos cartográficos, mas que estava à espera, sem desabar, mesmo que a condição imposta fosse não deixar de ser ponte. 


\title{
Caminho ou anoitecer
}

\begin{abstract}
Certa ocasião, foi anoitecer - era primeira vez, ou a milésima, não sei ao certo -, meus pensamentos andavam sempre a dar voltas, numa confusão. Num anoitecer de verão, em que o riacho murmurava, obscuro, ouvi passos de um ser humano. Vindo até mim, até mim. Estica-te, ponte; coloca-te em posição; mantém-te confiante, trave sem parapeito. Busca compensar-lhe, sem que ele perceba, a insegurança do passo; depois, dá-te a conhecer e, como um deus das montanhas, arroja-o à terra. (Kafka, 1985, p. 156)
\end{abstract}

Uma vez a ponte estendida, estabeleceu-se um caminho noturnal, repleto por rodopios de pensamentos na lógica kafkiana, que atravessaremos de encontro às nossas duas juventudes. Consideraremos para ambas partes os passos do percurso, de um "vindo até mim", assim como a postura que se estabeleceu até se travar o conhecimento entre elas, utilizando essas metáforas para descrever a fundamentação teórica e metodológica que norteou a experiência do estágio.

O projeto se fundamentou na psicologia social e na psicanálise em situações sociais críticas que se dedicam a desenvolver pesquisas e intervenções que visam ao cuidado de pessoas em situação de vulnerabilidade social. Trata-se do exercício de uma psicologia que extrapola a barreira do consultório particular, indo ao encontro da população que historicamente não teve acesso aos seus serviços; no esteio dessa perspectiva, encontramos autores que articulam essa posição do psicólogo social com a abordagem psicanalítica e apresentam a oferta de escuta qualificada que articula as narrativas de diferentes modos de sofrimento aos seus condicionantes subjetivos, sociais e históricos. Ou seja, as atividades desenvolvidas estão pautadas em duas noções principais: a escuta territorial (Broide \& Broide, 2015) e a dimensão sociopolítica do sofrimento (Rosa, 2016).

Escuta territorial é uma metodologia criada por Broide \& Broide (2015) baseada em um processo de escuta que ocorre no caminhar e conversar com os sujeitos no entorno de suas regiões de moradia e vivência, compreendendo o território não como um espaço geográfíco, mas sobretudo como campo de criação e circulação de relações. É uma prática de psicanálise ampliada, em espaços abertos, e que se pauta na potencialidade das comunidades, não apenas nas fragilidades, localizando os vínculos (pessoas, lugares, objetos ou eventos) que ligam as pessoas à sua dimensão desejante. Na escuta proposta pelos autores, identificam-se e valorizamse os nomeados "pontos de ancoragem" dos sujeitos, sendo eles os laços que os ligam ou reconectam à vida, mesmo diante de extrema vulnerabilidade social, interessando o que os mantêm vivo e sustenta sua elaboração de projetos de vida.

$\mathrm{Na}$ escuta territorial, as narrativas dos sujeitos não se associam apenas ao âmbito privado; ao contrário, seus afetos articulam-se às condições históricas e culturais da sociedade na qual se inserem e se retroalimentam. Rosa (2016) aponta essa dimensão sociopolítica do sofrimento, que demanda uma escuta do psicólogo que reconheça a dimensão desejante nas narrativas dos sujeitos que usualmente ocupam o lugar de resto na estrutura social. Ou seja, o psicólogo e psicanalista precisa exercitar um posicionamento substancialmente ético e político.

É uma intervenção que articula psicanálise e política e visa à criação de dispositivos que abordem a experiência dos sujeitos acometidos por conflitos sociais e políticos relacionados à opressão e à segregação social. A clínica psicanalítica se faz prática política por tomar como política não apenas sua faceta de poder e domínio, mas também como uma ação que se dá no espaço entre as relações, articulando-se na produção de um mundo comum (Rosa, 2016), na 
qual a singularidade do sujeito emerge diante da dimensão de fatos e acontecimentos históricos e econômicos da cena social (Broide \& Broide, 2015).

Para os autores, prevalece uma trama enredada em um modelo de sociedade neoliberal, de exclusão e silenciamento das pessoas em situação de vulnerabilidade social, que exige intervenções que criem condições de alterações do campo simbólico/imaginário - subjetivo, social e político - que visam transformações, mesmo que elas ocupem pequena parte nos jogos de poder, num plano de micropolítica, ao investir em mudanças subjetivas, em processos de produção subjetiva, ao inventar modalidades clínicas de enfrentamento de problemas políticos, que permitam saídas para singularização e que estimulem a capacidade desejante e suscitem o potencial de crítica para combate de práticas de assujeitamento.

Nesse sentido, a primeira movimentação dos estagiários pelas redondezas do CRAS partiu da ideia de mapear o território, no desejo de conhecer e conceber as interferências no campo, como uma espécie de bússola que pudesse apontar demandas e ações. Ela se mostrou uma iniciação à escuta territorial, em que as dimensões extrapolaram a materialidade do espaço, permitindo a apreensão dos territórios simbólicos e sociais, os mapas de afetos que com lógica própria articulavam-se aos processos de assujeitamento e subjetivação - uma concepção inicial de como era o espaço de existência daquela juventude, se existia de fato e como se expressava.

O caminho percorrido, descrito pelos relatos das juventudes sobre seu próprio território, mostrou-se feminino. Ao andarem pelas ruas da cidade, as adolescentes referiram como era a questão de gênero em suas casas e naquele espaço, como advinham de famílias chefiadas por mulheres ou com homens pouco presentes (a não ser em conflitos), como assumiam responsabilidades pelos cuidados com os irmãos e como era difícil a livre circulação pelo bairro. Atravessaram as falas questões de violência e assédio, o risco de escolha pelos meninos do tráfico e os corpos matáveis nos bailes funks e lançados na maré. Relataram como esses fatos eram dialogados no SCFV anterior, no espaço do CRAS, e como alguns jovens que participaram tomaram a direção do abandono escolar, do tráfico e da institucionalização (em centro socioeducativos, por conflitos com a lei, ou casas de acolhimento, por violação dos seus direitos). Sobretudo, manifestou-se a necessidade de contar essas histórias, falar do cotidiano e lidar com conflitos que emergiam, estabelecendo um espaço de pronunciamento das narrativas, que no desejo de expressão de uma juventude encontrasse o desejo de escuta da outra.

Pactuou-se entre juventudes e preceptora, assim, a retomada de um grupo de jovens que fizesse lugar ao antigo SCFV, mas com seus modos de operação próprios. A configuração estabeleceu-se em encontros semanais, com duração aproximada de 2 horas, abertos a jovens a partir de 12 anos, sem o estabelecimento de qualquer obrigatoriedade ou compromisso com frequência. Os jovens poderiam experimentar o espaço, verbalizar ou não suas questões, e o local de encontro seria o CRAS, mas com a permissão da exploração do território e da cidade. Os adolescentes foram convidados pelas técnicas do serviço, pelas duas adolescentes que incitaram o trabalho e pela abordagem dos estagiários, além de por um cartaz na movimentada recepção do CRAS que atiçava a curiosidade para uma nova ideia de trabalho no equipamento. Pela rotina movimentada das trabalhadoras, na qual se incluía a própria preceptora, o grupo foi conduzido sem a presença dos técnicos do CRAS, mas com a possibilidade de utilização do apoio da equipe e uso indiscriminado de todo o espaço.

Diferentemente do SCFV já experienciado na cidade, não havia a figura de um educador na condução, com propostas previamente delimitadas e, até certa medida, abrangentes e pedagógicas; não havia um cronograma de atividades com visitas monitoradas, passeios, 
excursões e eventos articulados pela Secretaria de Assistência Social - havia "apenas" o desejo de uma escuta que desse abertura a acontecimentos e desdobramentos, permitindo por si a direção do próprio trabalho.

As quintas-feiras, marcadas para os jovens, eram grandes acontecimentos no CRAS: havia a chegada dos estagiários, o preparo da sala, a expectativa da vinda (ou não) de jovens e as dúvidas quanto ao que se poderia construir naquele espaço. Em poucos encontros o grupo se desenhou: por volta de dez meninas, negras, pobres, periféricas que geralmente vinham acompanhadas pelas irmãs menores, trazendo também a infância para a cena. Do outro lado, os estagiários, também jovens, de classe média, universitários, brancos, com idades não tão distantes das anfitriãs no território.

Guerra (2019) defende a complexidade da concepção de juventude pela ideia de disjunção de elementos como o adultocentrismo para construção de modelos de trabalho, do adulto que toma o jovem para tratar dele; a suspeita de considerar o jovem sempre como incapaz de resposta; a redução da experiência da juventude à dimensão biológica ou política; a decisão de incluir ou não o jovem e seus enunciados no trabalho; se (ou como) tomamos a perspectiva de fundo na qual as juventudes inscrevem suas histórias. $\mathrm{Na}$ concepção da autora, não há possibilidade de conformidade desses diferentes planos de análise nem unificação em uma única matriz, por isso é importante afirmarmos que a juventude que consideramos aqui vem de uma construção de trabalho entre juventudes que inclui seus enunciados, em uma dimensão que considera a política e a conjuntura, logo envolve perceber a distância entre os discursos de uma juventude privilegiada e de outra marginalizada. Esta última é formada por "[...] sujeitos aos quais a organização social, quando identifica sua existência, atribui lugares marginais, pela falta de lugar no ideal social e a consequente perda de um discurso de pertinência, acentuada em situações não consideradas pelo discurso social" (Scarparo \& Poli, 2008, p.3)

São vozes que são desconsideradas, não ouvidas e silenciadas por denunciar a desigualdade estrutural que questões de gênero, raça e classe privilegiam, tornando alguns sujeitos valorativos em detrimento de outros. Rosa (2002) refere uma resistência na escuta dessas vozes de pessoas em vulnerabilidade social - na maioria negras, pobres e periféricas - justamente pelo caráter denunciante de suas falas, que na predisposição de ouvir nos faria reconhecer os elementos perversos dessa desigualdade que também nos favorece no sistema capitalista. Nesse campo simbólico em que se apresenta a resistência à escuta de histórias duras, que despertam muitas vezes o silenciamento mortífero, colocar-se como ouvinte é receber um convite à experiência do encontro e da invenção junto ao outro que, paradoxalmente, são movimentações de uma micropolítica de produção de vida.

A opção pelo trabalho grupal partiu da possibilidade do grupo enquanto espaço de arbitragem e alteridade, um continente para contradições, que permitiria construir projetos de vida e conviver com o risco de morte - paradoxos permanentes na trajetória desses sujeitos, fazendo assim do grupo uma égide de confiança, em um território fragmentário, de desamparo e muitas vezes de ausência do Estado (Broide \& Broide, 2010).

Os encontros foram marcados pelo compartilhamento de experiências das jovens, que traziam em grande parte a dificuldade de acesso à saúde, a insatisfação com o ambiente escolar e a violência nas relações familiares e comunitárias. A violência, marcada no discurso, emergiu também no contexto grupal das relações entre elas, por meio de verbalizações agressivas, interrupções de fala e embates físicos, sendo uma inquietação persistente para os universitários. O desafio era lidar com a expressão de uma violência encarnada e repetida e a dificuldade de 
abordar esse tema relacional que compunha o dentro e fora do grupo, enraizado nas condições sociais daquela juventude.

A violência, vislumbrada apenas como "produção de morte" e destruição, trazia aos universitários a necessidade urgente de uma intervenção no sentido de interromper ou ao menos alterar aquela manifestação, o que exigia perscrutar o mal-estar que aquela violência produzia neles e na resistência de escuta, e o lugar daquela expressão para a juventude periférica - uma violência que poderia ter uma faceta de resistência contra um sistema que violenta cotidianamente, uma agressividade com

\footnotetext{
função de produzir distinções, de marcar diferenças - entre o que é o eu e o não eu - [que] muitas vezes, opera como uma defesa contra o assujeitamento ou captura no desejo do outro [...] como uma necessidade de provocar no outro a desordem que se sente operando em si próprio. (Vicentin, 2016, p.38)
}

Para Vicentin (2016), a agressividade pode ser uma expressão dramática dos contextos de vida das crianças e adolescentes quando os modos de dizer não cabem nos corpos ou territórios existenciais e sociais, portanto, quando não há outros dispositivos de expressão. Dessa maneira, a substituição da palavra pela violência ou mesmo a opção da violência por meio da palavra pode revelar um receio de um mutismo quando ainda não se acham palavras para expressar o vivido - são violência e agressividade que podem ser uma tentativa de solução, uma estratégia de existência, formas de criar derivas ante imperativos e projetos homogeneizadores, brechas que podem instaurar trabalhos de subjetivação na clínica.

Conceber a violência com seus outros contornos e leituras conduziu o olhar no estágio para a agressividade dos jovens como meio de comunicar o assujeitamento e destituição discursiva nessa conjuntura, em que lhe são violados seus direitos de existência e na direção de apostar na inventividade permanente para converter agressividade em matéria geradora de vida (Vicentin, 2016). É uma prática de Psicologia na assistência social que, no impeditivo de uma clínica privativa (CFP, 2007), se propôs a uma escuta clínico-política (Rosa, 2016), que considerou a escuta desses sujeitos e seus lugares no laço social, acolhendo seus silêncios e suas outras ordens de pronunciamento, permeada de afetos.

Foi uma via elegida que abriu possibilidade para palavra, mas também permitiu a experimentação corporal da presença, do lúdico e da construção coletiva, de modo que a agressividade e violência, em poucos encontros, deram brechas também para brincadeiras, jogos, danças e músicas, outras maneiras de pronunciamento da juventude. Um rastro desses momentos como dispositivo de expressão aconteceu em uma tarde: em meio a uma "guerra de bexigas d'água" no CRAS, testemunhada pela preceptora e repercutida na equipe do serviço, uma das adolescentes verbalizou espontaneamente: "Tia, Bolsonaro vai matar nós tudo [...] porque ele vai matar os negros, e eu sou negra. Quer dizer... não sou tão escura assim, mas ele vai matar nós tudo".

A verbalização ocorreu após o intenso processo eleitoral de 2018, logo depois do $2^{\circ}$ turno das eleições, em que nos sentíamos no CRAS asfixiados pelo contexto político e derrotados com o resultado da eleição presidencial. As promessas genocidas do então recém-eleito, Jair Bolsonaro, eram pautas constantes de conversas das equipes, dos estagiários, das famílias, mas nos escapou o impacto das eleições para aquelas crianças e adolescentes que acompanhavam no cotidiano a invalidação de seus modos de viver e o desvalor de suas próprias vidas, em uma 
banalidade da morte. Elas tinham seus temores, suas fantasias, para os quais só acharam palavras após a guerra de bexigas, e que nos coube ouvir, acolher e problematizar, construindo modos de resistência a uma opressão claramente anunciada.

Havia ameaças às pessoas em situações sociais críticas e, consequentemente, aos espaços construídos para a garantia de seus direitos, isto porque, mesmo com a alteração substancial em sua configuração, que se sustentou no objetivo de superar o assistencialismo histórico e atingir o âmbito de direitos sociais (Constituição da República Federativa do Brasil, 1988; Lei n. 8742, 1993), a política de assistência social permaneceu subjugada aos interesses político-partidários. A isso anuímos com a alteração significativa de seu escopo, dimensão e configuração administrativa na Era Lula (2003-2010), com uma implantação, em 2005, permeada por diversas dificuldades em mínimos de exigência, com uma continuidade marcada pela precariedade no governo de Dilma Rousseff (2011-2016), e com a perda de forças e ameaças de desmonte no governo Temer (2016-2018).

O Governo Bolsonaro (2018 - presente) não apresentou propostas para a assistência social e tinha e manteve posicionamentos evidentes de exclusão social, com discursos de ódio direcionados às pessoas marginalizadas. O SUAS desenhou um futuro de assistência social no país em 2005, mas com uma necessidade de aprimoramento enquanto conquista cotidiana, de exigência de investimentos crescentes, que em uma implantação e consolidação frágil não tem garantido sua sobrevivência nesse período de desmandos: ao contrário, acompanhamos a política pública citada como uma verdadeira corda bamba em que os prejudicados são exatamente os mais vulneráveis socialmente.

Ao promover brechas para o pronunciamento das histórias de abandono social dessas crianças e adolescentes, dando suporte aos meios de sua expressão, pode-se criar condições para a transmutação dos gestos em palavras, de uma dor sem palavras, lugar dos discursos que os retiram da condição de sujeitos pelo excesso de privação, garantindo espaço para a manifestação de um sofrimento sociopolítico.

Nessa travessia, tal como a ponte, as juventudes se encontraram, inicialmente confusas ao dar voltas até o outro. Foram passos de um ser humano, porque no endurecimento inicial talvez não houvesse ainda esse elemento humanizador do contato, como naquele protagonista-inseto inicial de Kafka, acompanhante das andanças da preceptora. Nesse "vindo até" o outro, os jovens estagiários e as juventudes periféricas precisaram se esticar para o encontro, localizar uma posição confiante, mesmo que para encobrir as inseguranças dos passos, e se deram a conhecer na permissão mútua ao lançamento, sem receio da queda.

\section{Destino ou uma ponte vira-se!}

\footnotetext{
Ele veio, percutiu-me com a ponta de ferro de sua bengala; a seguir, ergueu com ela as abas de minha casaca e as arrumou sobre mim. Correu a ponta da bengala pelo meu cabelo ramalhudo e, provavelmente olhando espantado à volta, deixou-a ali ficar por longo tempo. Mas por fim - eu o sonhara por montes e vales - pulou com ambos os pés para o meio do meu corpo. Totalmente ignorante, experimentei dor intensa. Quem era ele? Uma criança? Um sonho? Um salteador? Um suicida? Um tentador? Um exterminador? E virei-me para olhá-lo. - Uma ponte vira-se! Não chegara ainda a virar quando despenquei; despenquei e pronto me rasgaram e me furaram a carne os seixos pontudos que sempre me haviam fitado tão serenamente de dentro das águas frenéticas. (Kafka, 1985, p. 156)
} 
No conto, Kafka (1985) menciona alguém que se coloca como passarela que é atravessada por outro que se faz triunfante nesse percurso - uma passarela que se exibe como percurso, mas não deixa de contemplar o que acontece, o que lhe acontece, e que, no ápice da narrativa no conto, quando ocorre o salto do transeunte, o que é atingido é a parte central do seu corpo, algo como um soco no estômago que tira o fôlego e faz perder as forças.

A ponte de condição rija então flexibiliza, encara o desconhecido e vira-se, e na total contradição de "uma ponte que se vira", desaba e se desfaz. Nesse recorte, decidido para descrever nosso destino não como fim do trajeto, mas fechamento de uma vivência, tomamos por base uma queda: do conhecido, de uma desconstrução de abertura à alteridade e produção do comum, que permeou resultados dessa experiência do estágio.

Após a declaração que trouxe a presença iminente da morte na cena e colocou palavras no despedaçamento, pudemos perceber o vínculo transferencial estabelecido nas relações entre estagiários-crianças e adolescentes, estagiários-espaço institucional, equipe-estágio e equipejuventude. Foi como se a revelação de uma violência sentida mas não dita tivesse descortinado os episódios de violência cotidianos, em que lançamos e somos lançados, quando silenciamos as pessoas em situação de vulnerabilidade social (Rosa, 2016).

Durante a continuidade do estágio, o grupo entre juventudes percorreu o território, visitando uma das famílias, tomando banhos no mangue, brincando nas praças e indo à universidade, em duas oportunidades, conhecer o espaço educacional e participar de atividades. Nessas andanças, as trabalhadoras do CRAS, inclusive a própria preceptora, permaneceram quase sempre no equipamento, mas não isentas do impacto dessa experiência. É importante frisar que no início houve estranhamento do restante da equipe com a movimentação e quebra de rotina, até certo desconforto pela modificação do espaço, o que gradativamente foi dando lugar para reconhecimento das crianças e adolescentes por meio de cumprimentos, acompanhamentos discretos das atividades e até pela livre circulação do grupo por todo e qualquer espaço do serviço, tida com a naturalidade devida.

O auge foi a participação do grupo de jovens na Conferência Municipal da Criança e Adolescente do município, uma estratégia de participação social que prevê a construção de propostas para as políticas públicas, que passam por etapas municipais, estaduais e federais. Em um dia de forte sol, a juventude do território encontrou-se bem cedo com os estagiários no CRAS, e de lá foram andando aproximadamente $9 \mathrm{~km}$ até o centro da cidade para participar da conferência. Participaram ativamente do encontro, levando propostas e conseguindo a eleição de uma criança e uma adolescente do grupo como representantes municipais para as próximas etapas. Voltaram para o serviço novamente andando e prepararam junto aos estagiários um almoço no CRAS; depois de comer apressadamente, montaram lanches e retornaram ao centro a pé, para passar o restinho da tarde na praia, retornando quase no começo da noite.

Foram quase $36 \mathrm{~km}$ percorridos pelas juventudes naquele dia, interligados ao serviço, que a equipe acompanhou pelas fotos das ruas dos bairros de abrangência, das crianças e adolescentes rindo pelo centro em poses variadas, dos abraços com os estagiários, dos momentos nos palanques da conferência, do almoço sentados no chão da sala de reunião e, principalmente, das caras cansadas, mas de sorrisos largos. Naquele dia, a preceptora chorou um pouco apreensiva, e muito se percebeu das expressões da equipe entre sorrisos, suspiros e encantamentos. Em que momento contribuímos para transformar diferenças em desigualdades? Como protocolos e servidão às normas podem estar acima de vínculos e territórios existenciais? Como olhamos sempre para o abismo e a morte, ignorando que existem pontes que produzem vida? 
Paradoxalmente, diante de um território marcado pela falta de recursos socioeconômicos, pela violência física e simbólica e pelo desamparo social, ter por base a dimensão sociopolítica do sofrimento e suas projeções mortíferas (Rosa, 2016) foi também encontrar pontos em que a vida se sustentava (Broide \& Broide, 2015), em um processo entrelaçado à noção daquilo que potencializa vida. Em meio à falta de dispositivos de expressão, recorrer à inventividade, conduzindo o trabalho na direção da possibilidade, da criação e do desejo que se faz no encontro e no coletivo, trouxe a “ $[. .$.$] potência de sustentação mútua daquilo que nos garante ligação$ com o outro: garante-nos inventar diferentes espaços possíveis de existência" (Vicentin, 2016, p. 40). Para Vicentin (2016), é um trabalho que não se realiza isolado pelo risco de sermos afetados pelo feitiço sedativo que a exclusão faz recair sobre nós, atando nossas mãos diante da miséria e da violência, de forma que coletivizar contribui para romper com o fatalismo, ampliando a potência e capacidade de nos afetarmos e nos responsabilizarmos pela vida de outros.

Podemos dizer que o trabalho se constituiu de forma coletiva, por muitas mãos - das crianças, adolescentes, estagiários, preceptora, supervisores de estágio e, até, da equipe do serviço -, na construção de espaços de cuidado, confiança, acolhimento em que o exercício da possibilidade da palavra e a abertura para escuta e expressão do outro contribuíram para a aproximação de desejos, perspectivas e projetos de vida em todos os envolvidos. De uma experiência tão intensa de encontros e vínculos não se esperava uma despedida que não deixasse silêncios, lágrimas e abraços em todos os seus desfechos (último encontro do grupo de jovens, último dia de estágio e último encontro de supervisão) - abraços que, nesse momento, pareciam carregar histórias compartilhadas. $\mathrm{Na}$ dureza da vida e rigidez das instituições pareceram revelar-se apontamentos à inventividade de criação de novas práticas “emparceiradas" por uma rede de afetos.

Isso remete à virada do conto kafkiano, em que nosso narrador-ponte se mantém firme quando sozinho, mas no momento de curiosidade e mortificação por sua inauguração de passagem e encontro com o outro tenta olhar o céu e com isso cai - um céu que pode ter um quê de desejo e uma queda que pode figurar um desligamento do real, uma história em cujo processo de construir dispositivos de cuidado para juventudes na assistência social, as imagens parecem ser sonhadas por todos juntos, em um sonho em que se permitir descobrir, correr risco, se rasgar e conceber marcas vai ao encontro da prática clínico-política defendida para o campo de atuação.

\section{Considerações finais}

E por falar em sonhos, a metáfora da ponte parece simbolizar essa interligação de sonho e realidade, de pés no real e mãos no sentir, tocar e desejar, sendo o protagonista do texto o elo entre esses elementos, de agir e esperar, resistir e desistir, integrar ou se desmanchar ao primeiro toque. A literatura kafkiana, em primeira leitura, pode parecer trágica, angustiada ou mesmo apolítica, mas Kafka foi um autor que deu espaço para as inquietudes do homem do seu século, em universos sufocantes e opressivos, de indivíduos solitários e imponentes diante da burocracia, da justiça, do poder e da sociedade. É uma obra de enunciações coletivas, em que becos sem saída são linhas de fuga viva e criadora, ainda que no mesmo lugar e sem significar liberdade (Deleuze \& Guattari, 1977). 
Com norteadores de uma escuta territorial (Broide \& Broide, 2015), de uma prática clínicopolítica de manejo de um sofrimento sociopolítico (Rosa, 2012, 2016), o grupo entre juventudes se delineou como possível linha de saída no campo da experiência, em uma psicanálise com alçada no diálogo, espaço para dar voz às palavras, mas para além disso, criar novas formas de relação. Tendo como escopo primordial a dimensão desejante das crianças e adolescentes, no começo, parecia muito difícil localizar essa esfera, como se não houve permissão anterior para ela. A predisposição para uma proposta aberta, de conversas longas, atravessadas ou interrompidas, e até mesmo demonstrações abalroadas, foi tomando formas de cuidado no grupo, apontando que talvez também não estivéssemos completamente prontos para a manifestação desses desejos.

Ao se permitir lançar em uma espécie de violência instigada pelo encontro, traçou-se um jogo de sensibilidade e criação, de escuta e presença, acerca de uma prática clínica que sustentasse aproximações e afastamento, aceitando as marcas deixadas nesse interjogo. Era necessário não deixar as crianças e adolescentes no desamparo ou abandono mesmo quando sua dor ganhava o corpo e palavras, em um espaço descrito, por uma delas, assim: "Aqui a gente pode ser o que quiser, pode falar o que quiser que vocês não vão julgar". Nesse espaço "do que quiser", estabeleceu-se uma tessitura de confiança e apoio, que diante da morte buscou recursos disponíveis na própria comunidade, no tecido comunitário, para fazer emergir a vida (Broide \& Broide, 2015).

Estabeleceu-se uma clínica das juventudes, um espaço de troca e pertencimento, que agora podemos notar nasceu justamente da escuta do desejo, de duas adolescentes de retomar o SCFV, uma aproximação ao trabalho do PAIF, alicerce da proteção social básica, mas ainda um desafio na execução pública de uma assistência social precarizada. Tomar os registros vivenciados para intervenções psicanalíticas clínico-políticas na arena socioassistencial significa investir em uma formação profissional direcionada para um compromisso com uma atuação em Psicologia voltada para transformação de territórios e realidades materiais e simbólicas, redimensionando e ampliando o repertório pessoal - de uma presença comprometida politicamente frente ao mundo - e teórico - de edificação de intervenções empenhadas em combater desigualdades sociais.

É necessário um alargamento de compreensão que permeia a construção da profissão de psicólogo, da formação acadêmica até o desenvolvimento da carreira, confirmando a importância de experiências de estágio nessa direção, na assistência social, e compondo, inclusive, a educação permanente no SUAS. É necessária tal ênfase, pois, por vezes, nós profissionais somos resistentes à interlocução com a universidade e à presença de estagiários no campo, percebendo isso como encargo e desconsiderando as muitas contribuições dessa interlocução para alterações no campo de trabalho. É uma chave de leitura que se desnuda extremamente equivocada no revistar de nossa experiência, em que por meio do apoio da universidade e da disposição dos estagiários em campo em estabelecer um lugar de escuta e fala, abriram-se possibilidades de romper silenciamentos e formas de expressão da violência, modos de atuação que defrontam a burocratização e enrijecimento identificados na área pela preceptoria de estágio.

Como um peso que se converte em leveza, no encontro entre jovens universitários e a materialidade dos jovens periféricos, na experiência de estágio, foi possível tecer um sonho entre juventudes pela convivência, mesmo que por vezes embaraçado ou desfeito, capazes de fazer marcas e perdurar no tempo. Esclarecemos que, na despedida dos estagiários, havia na 
ocasião um contraponto: "Tudo parte do desejo delas, mas como ir embora, depois do que foi vivenciado, sentido e construído?”. A resposta veio meses depois, no ano seguinte, pela criação de um grupo de teatro com a iniciativa das mesmas jovens em luta pela vida em parceria com o CRAS e o SCFV de uma instituição do território, com o teatro como oportunidade de uma arte menor crítica e inventiva, de colocar palavras, imagens e gestos naquele sonho desvelado pela experiência.

E não se trata de pensar a Psicologia de forma messiânica: ao contrário, trata-se de refletirmos sobre o exercício da profissão em seu próprio limite, pela crítica, pelo tensionar ao máximo as contradições de uma clínica tradicional idealizada no seio das desigualdades capitalistas e na visão dicotomizada de causa-efeito do sofrimento humano, quando se mostra muito mais como manifestação singular da totalidade social. Sonhamos com um fazer psicanalítico que se transmute em ponte e caminhante, que verifique e permita explorar, que olhe para o chão, sem esquecer virar-se para encarar o céu.

\section{Referências}

Adorno, T. (1998). Anotações sobre Kafka. Prisma: crítica cultural e sociedade (pp. 239-280). São Paulo: Ática.

Benjamin, W. (1985). Franz Kakfa. A propósito do décimo aniversário de sua morte. In W. Benjamin. Magia e técnica, arte e política. Obras escolhidas I (pp. 132-164). São Paulo: Brasiliense.

Broide, E., \& Broide, J. (2010). Psicanálise: nas situações sociais críticas. Violência, juventude e periferia: em uma abordagem grupal. $1^{a}$ reimp. Curitiba: Juruá.

Broide, E., \& Broide, J. (2015). A psicanálise em situações sociais críticas: metodologia clínica e intervenções. 2. ed. São Paulo: Escuta.

Conselho Federal de Psicologia (CFP). (2007). Referência técnicas para atuação do(a) psicólogo(a) no CRAS/SUAS. Brasília: CFP.

Conselho Federal de Psicologia (CFP). (2011). Como os psicólogos e as psicólogas podem contribuir para avançar o Sistema Único de Assistência Social (SUAS) - Informações para gestoras e gestores. Brasília: CFP.

Conselho Federal de Psicologia (CFP). (2013). Referências técnicas para prática de psicólogas(os) no Centro de Referência Especializado da Assistência Social. Brasília: CFP.

Conselho Nacional de Assistência Social. (2005). Política nacional de assistência social. Brasília: Conselho Nacional de Assistência Social.

Constituição da República Federativa do Brasil. (1988). Brasília, DF: Senado Federal.

Deleuze, G., Guattari, F. (1977). Kafka por uma literatura menor. Rio de Janeiro: Imago.

Guerra, A. M. C. (2019). Alguns princípios teórico-políticos para intervenções com a juventude: como lidar com os efeitos psicossociais da violência? In M. L. G. et al. (Orgs.). Corpos que sofrem: como lidar com os efeitos psicossociais da violência? (pp. 137-149). São Paulo: Elefante.

Kafka, F. (1985). A ponte. In F. Kafka. Os buracos da máscara: antologia de contos fantásticos (pp.158-157). São Paulo: Brasiliense. 
Kafka, F. (1997). A metamorfose. São Paulo: Companhia das Letras.

Lei n. 8742. (7 de dezembro de 1993). Dispõe sobre a organização da assistência social e dá outras providências. Lei orgânica da assistência social. Brasília, DF: Presidência da República. Casa Civil. Subchefia para Assuntos Jurídicos.

Ministério do Desenvolvimento Social e Combate à Fome (MDS). (2006). Norma operacional básica - NOB/SUAS. Brasília, DF: Ministério do Desenvolvimento Social e Combate à Fome.

Ministério do Desenvolvimento Social e Combate à Fome (MDS). (2012). Orientações técnicas sobre o PAIF: o serviço de Proteção e Atendimento Integral à Família, segundo a tipificação dos serviços socioassistenciais. v. 1. Brasília, DF: Ministério do Desenvolvimento Social e Combate à Fome.

Ministério do Desenvolvimento Social e Combate à Fome (MDS). (2013). Perguntas frequentes: serviço de convivência e fortalecimento de vínculos. Brasília, DF: Ministério do Desenvolvimento Social e Combate à Fome.

Pinto, D.K.S. (2017). A possivel metamorfose da Psicologia na Assistência Social: um estudo da prática e seus sentidos na cidade de São Vicente/SP (Dissertação de Mestrado Profissional em Ensino em Ciências da Saúde). Instituto Saúde e Sociedade, Universidade Federal de São Paulo, São Paulo.

Rosa, M. D. (2002).Uma escuta psicanalítica das vidas secas. Textura: Revista de Psicanálise, 2(2), 42-46.

Rosa, M. D. (2016). A clínica psicanalítica em face da dimensão sociopolítica do sofrimento. São Paulo: Escuta/Fapesp.

Scarparo, M. L. D. E., \& Poli, M. C. (2008). Psicanálise e assistência social: uma escuta psicanalítica. In III Congresso Internacional de Psicopatologia Fundamental e IX Congresso Nacional de Psicopatologia Fundamental, Niterói, RJ.

Vicentin, M. C. (2016). Criançar o descriançável. In Secretaria Municipal de Educação. Coordenadoria Pedagógica. Núcleo de Apoio e Acompanhamento para Aprendizagem. Caderno de debates do NAAPA: questões do cotidiano escolar. São Paulo: SME / Coped.

Revisão gramatical: Gabriela Garcia Maloucaze

E-mail: gabriela.ngm@gmail.com

Recebido em novembro de 2020. - Aceito em outubro de 2021. 